\title{
ASISTENSI PENGGUNAAN PENDEKATAN KONSTRUKTIVISME DENGAN MEDIA PENDAMPING EDMODO UNTUK GURU SMA/MA MGMP EKONOMI SE-KOTA PADANG
}

\author{
Sri Wahyuni' ${ }^{1}$, Jimi Ronald ${ }^{2}$, Vivina Eprillison ${ }^{3}$, Mona Amelia ${ }^{4}$, Dio Fernando ${ }^{5}$ \\ ${ }_{1,2,3,4}$ STKIP PGRI Sumatera Barat \\ *E-mail: sriwahyuniajeng4@gmail.com, jimironaldstkippgrisumbargmail.com, \\ monaamelia8625@gmail.com, vivina.eprillison@gamail.com
}

Submited: 2019.01.23 Reviewed: 2019.01.28 Accepted:2019.06.30

https://doi.org/10.22202/rangkiang.2019.v1.i1.37334

\begin{abstract}
Currently there are a variety of new innovations in the world of education, especially in the learning process. One such innovation is constructivism. The choice of approach is more so that learning makes students enthusiastic about existing problems so they want to try to solve the problem. Classroom learning that uses constructivism, will make students empowered by the knowledge within them. They share strategies and solutions, debate one another, think critically about the best way to solve each problem. In this case Edmodo provides an environment where teaching and learning can produce student excitement that will make students more independent without forgetting the standards for measuring student success. It is undeniable that students will like learning through this platform, and when students feel comfortable, their desire to be able to understand new material, and the spirit of overcoming difficulties will increase in the learning process. Edmodo is one of the ways to build student enthusiasm for learning. Edmodo can help teachers build a virtual classroom based on the division of real classes in schools, where in the class there are assignments, quizzes, and grading at the end of each learning.
\end{abstract}

Keywords: construktivism, edmodo

\section{ABSTRAK}

Saat ini terdapat beragam inovasi baru di dalam dunia pendidikan terutama pada proses pembelajaran. Salah satu inovasi tersebut adalah konstruktivisme. Pemilihan pendekatan ini lebih dikarenakan agar pembelajaran membuat siswa antusias terhadap persoalan yang ada sehingga mereka mau mencoba memecahkan persoalannya. Pembelajaran dikelas yang menggunakan konstruktivisme, akan membuat para siswa diberdayakan oleh pengetahuannya yang berada dalam diri mereka. Mereka berbagi strategi dan penyelesaian, debat antara satu dengan lainnya, berfikir secara kritis tentang cara terbaik untuk menyelesaikan setiap masalah .Dalam hal ini edmodo menyediakan lingkungan dimana mengajar dan belajar dapat menghasilkan kegembiraan siswa akan membuat siswa menjadi lebih mandiri tanpa melupakan standarpengukuran keberhasilan siswa. Tidak dapat dipungkiri bahwa siswa akan menyukai pembelajaran lewat platform ini, dan ketika siswa merasa senan, maka keinginan mereka untuk dapat memahami materi baru, dan semangat mengatasi kesulitan akan semakin meningkat dalam proses pembelajaran tersebut. Edmodo adalah salahsatu cara untuk membangun semangat siswa untuk belajar. Edmodo dapat membantu pengajar membangun sebuah kelas virtual berdasarkan pembagian kelas nyata di sekolah, dimana dalam kelas tersebut terdapat penugasan, quiz, dan pemberian nilai pada setiap akhir pembelajaran.

Kata Kunci: konstruktivisme, Edmodo

\section{PENDAHULUAN}

Saat ini terdapat beragam inovasi baru di dalam dunia pendidikan terutama pada proses pembelajaran. Salah satu inovasi tersebut adalah konstruktivisme. Pemilihan pendekatan ini lebih dikarenakan agar pembelajaran membuat siswa antusias terhadap persoalan yang ada sehingga mereka mau mencoba memecahkan persoalannya. Model pembelajaran konstruktivisme adalah salah satu pandangan tentang proses pembelajaran yang menyatakan bahwa dalam proses belajar (perolehan pengetahuan) diawali dengan terjadinya konflik kognitif. Konflik kognitif ini hanya dapat diatasi melalui pengetahuan akan dibangun sendiri oleh anak 
Vol. 1 (Juni 2019): 35 - 39

melalui pengalamannya dari hasil interaksi dengan lingkungannya. Salah satunya penggunaan edmodo di sekolah. Edmodo merupakan aplikasi yang menarik bagi guru dan siswa dengan elemen sosial yang menyerupai facebook, tapi sesungguhnya ada nilai lebih besar dalam aplikasi edukasi berbasis jejaring sosial ini.Edmodo seperti alat bantu belajar lainnya, bisamenjadi hanya sebuah platform online untuk mendorong pembelajaran guru, atau dapat menjadi cara lebih kreatif untuk melibatkan para siswa dalam pembelajaran kolaboratif dan kognisi terdistribusi.

Pada hakikatnya platform ini adalah mudah dipelajari dan mudah digunakan terutama bagi para guru yang menganggap dirinya berada diluar basis pengetahuan teknologi yang berkembang saat ini. Edmodo menyediakan lingkungan di mana mengajar dan belajar dapat menghasilkan kegembiraan siswa, siswa menjadi lebih mandiri, tanpa melupakan standar pengukuran keberhasilan siswa. Tidak dapat dipungkiri bahwa siswa akan menyukai pembelajaran lewat platform ini, dan ketika siswa merasa senang keinginan mereka untuk dapat mengatasi materi baru dan sulit akan meningkat. Edmodo adalah salah satu cara untuk membangun semangat siswa untuk belajar. Edmodo dapat membantu pengajar membangun sebuah kelas virtual berdasarkan pembagian kelas nyata di sekolah, dimana dalam kelas tersebut terdapat penugasan, quiz, dan pemberian nilai pada setiap akhir pembelajaran.

Dalam hal ini, permasalahan yang ditemui yaitu ada beberapa guru yang hanya memanfaatkan LCD proyektor untuk menampilkan slide-slide materi yang sudah dibuat dan hanya menerangkan di depan kelas saja. Hal ini dapat membuat siswa yang duduk paling belakang mengalihkan perhatian mereka dan tidak fokus terhadap penjelasan guru. Cara guru yang hanya menguasai media pembelajaran dan model pembelajaran yang biasa ini bisa mempengaruhi motivasi belajar siswa terhadap mata kuliah dasar-dasar pemrograman. Saat diberikan sebuah tes pun siswa masih menggunakan cara lama yang harus menyiapkan kertas dan membuat jawaban di atas kertas lembaran, hal ini dapat membuat siswa merasa malas. Guru hanya menggunakan metode dan media pembelajaran yang biasa membuat siswa merasa malas dalam mencari pengetahuan tentang materi pelajaran ekonomi. Dengan penggunaan media pembelajaran Edmodo, siswa dapat belajar mandiri dalam mengerjakan soal-soal tes yang diberikan. Metode pembelajaran kontruktivisme sangatlah dibutuhkan untuk membuat siswa menjadi lebih aktif dan bersemangat dalam belajar, baik di kelas maupun di luar kelas.

\section{A. PELAKSANAAN DAN METODE}

Metode pelaksanaan pengabdian pada masyarakat ini adalah menjelaskan solusi yang ditawarkan untuk membantu guru dalam membantu proses pembelajaran siswa di dalam kelas melalui pendekatan konstruktivisme dengan menggunakan media pendamping edmodo. Hal-hal yang akan dilakukan dalam penyelesaian masalah pada latar belakang adalah:

1. Memberikan pelatihan mengenai pendekatan pembelajaran yang sesuai untuk CTL.

2. Diskusi dan Tanya jawab

a. Materi yang akan disampaikan terkait konsep pendekatan konstruktivisme dan konsep media edmodo.

b. Permasalahan yang dihadapi para guru agar mampu menerapkan pendekatan Konstruktivisme dengan menggunakan media pendamping edmodo untuk membantu proses pembelajaran di dalam kelas.

Adapun prosedur kerja dalam realisasi program pengabdian ini adalah:

1. Membuat perencanaan materi yang akan di sampaikan

2. Penyajian materi sesuai dengan perencanaan materi yang telah disiapkan. Penyajian dilakukan dengan metode ceramah dibantu dengan media power point, diskusi dan paripurna.

3. Pelatihan dan bimbingan individual.

Untuk melaksanakan kegiatan PPM ini, rencana yang telah disusun dapat dijelaskan melalui tahapan sebagai berikut:

1. Tahap Persiapan

Kegiatan yang dilakukan pada persiapan ini adalah:

a. Pemantapan jadwal yaitu penentuan jadwal konkrit bersama mitra setelah usulan kegiatan disetujui untuk dilaksanakan.

b. Koordinasi dengan kelurahan mitra untuk melakukan pengurusan izin pelaksanaan kegiatan. 
Vol. 1 (Juni 2019): $36-40$

c. Penetapan peserta: penetapan peserta dilakukan dengan bekerjasama dengan Ketua MGMP se-kota Padang. Jumlah peserta yang dilibatkan dalam pelatihan adalah sebanyak 30 orang.

d. Menghubungi instruktur dan pembicara dan menyesuaikan jadwal pelaksanaan.

2. Pelaksanaan kegiatan

Pada saat kegiatan peserta dibekali dengan satu set ATK (Alat Tulis Kantor) untuk lebih memaksimalkan pelatihan. Selain itu, dalam pelaksanaan kegiatan ini Guru Ekonomi MGMP se-kota Padang mitra akan diberi modul yang berisi tentang materi.

3. Tahap akhir kegiatan

Pada tahap ini dilakukan kegiatan observasi dan evaluasi. Observasi dilakukan terhadap kemampuan Guru Ekonomi MGMP se-kota Padang ide dan peluang bisnis dan menuangkannya dalam bisnis plan.

Dalam kegiatan ini yang menjadi mitra adalah Guru Ekonomi MGMP se-kota Padang. Kerjasama dengan mitra ditandatangani oleh Ketua MGMP se-kota Padang.

\section{Tabel 1. Partisipasi Mitra Dalam Pelaksanaan Program}

\begin{tabular}{|c|c|c|c|}
\hline \multirow[t]{2}{*}{ No. } & \multirow[t]{2}{*}{ Tahap Kegiatan } & \multicolumn{2}{|l|}{ Partisipasi } \\
\hline & & Ketua Tim & Peserta \\
\hline 1. & Sebelum usulan diajukan & $\begin{array}{l}\text { Bersama tim pelaksana menentukan masalah } \\
\text { yang akan dipecahkan }\end{array}$ & \\
\hline 2. & $\begin{array}{l}\text { Persiapan administrasi } \\
\text { dan penetapan peserta }\end{array}$ & $\begin{array}{l}\text { Bersama tim pelaksana: } \\
\text { a. Memantapkan jadwal kegiatan } \\
\text { b. Pengurusan izin pelaksanaan kegiatan } \\
\text { c. Penetapan peserta }\end{array}$ & $\begin{array}{l}\text { Mendaftar untuk ikut } \\
\text { sebagai peserta } \\
\text { pelatihan } \\
\text { dengan sukarela }\end{array}$ \\
\hline 3. & Pembuatan materi & $\begin{array}{l}\text { Bersama tim pelaksana merumuskan materi } \\
\text { yang akan disampaikan }\end{array}$ & \\
\hline 4. & Penyajian materi & Monitoring pelaksanaan kegiatan & $\begin{array}{l}\text { - } \text { Mengamati, } \\
\text { mendengarkan, } \\
\text { - Mencatat dan } \\
\text { bertanya apabila } \\
\text { kurang paham } \\
\text { - Aktif dalam kegiatan } \\
\text { diskusi }\end{array}$ \\
\hline 5. & Pelatihan & $\begin{array}{l}\text { Monitoring pelaksanaan } \\
\text { Kegiatan }\end{array}$ & $\begin{array}{l}\text { Aktif dalam } \\
\text { melaksanakan } \\
\text { kegiatan sesuai dengan } \\
\text { materi pelatihan }\end{array}$ \\
\hline 6. & $\begin{array}{l}\text { Evaluasi ketercapaian } \\
\text { Tujuan }\end{array}$ & $\begin{array}{l}\text { Bersama tim pelaksana melaksanakan } \\
\text { evaluasi ketercapaian tujuan }\end{array}$ & \\
\hline
\end{tabular}

\section{HASIL DAN PEMBAHASAN}

Edmodo dapat dilihat sebagai Learning Management System (LMS) yang dapat memfasilitasi guru untuk membuat dan mengatur kelas online mereka secara mudah. Situs ini menyediakan cara yang sederhana untuk guru dan siswa agar dapat terhubung dan kerjasama secara virtual. Edmodo adalah platform pembelajaran yang aman bagi guru, siswa dan sekolah berbasis sosial media. Edmodo menyediakan cara yang aman dan mudah bagi kelas untuk terhubung dan berkolaborasi antara siswa dengan guru untuk berbagi konten pendidikan, mengelola proyek dan tugas dan menangani pemberitahuan setiap aktivitas yang akan dilaksanakan.

Dalam proses belajar mengajar diperlukan suatu cara atau metode untuk mencapai tujuan belajar. Menurut Hamalik (2003:2) metode mengajar adalah suatu cara, teknik atau langkah-langkah yang akan ditempuh dalam proses belajar mengajar. Sedangkan Roestiyah (2001:1) Metode mengajar adalah teknik 
Rangkiang: Lurnal Pengabdian Pada Masyarakat UPSM STKIP PER/ Sumatera Barat

Vol. 1 (Juni 2019): $35-39$

penyajian yang dikuasai guru untuk mengajar atau menyajikan bahan pelajaran kepada siswa di dalam kelas agar pelajaran tersebut dapat ditangkap, dipahami dan digunakan oleh siswa dengan baik.

Maka dari permasalahan tersebut, tim telah selesai melaksanakan pengabdian dengan konsep penggunaan pendekatan konstruktivisme dengan media pendamping edmodo yang bisa mengembangkan keaktifan siswa dalam mengkonstruk pengetahuannya sendiri, sehingga dengan pengetahuan yang dimilikinya peserta didik bisa lebih memaknai pembelajaran karena dihubungkan dengan konsepsi awal yang dimiliki siswa dan pengalaman yang siswa peroleh dari lingkungan kehidupannya sehari-hari.

Pengabdian ini juga bertujuan membantu guru dalam menunjang proses pembelajaran aktif di kelas menggunakan pembelajaran konstruktivisme dengan media pendamping edmodo sebagai media e-learning guru dalam proses pembelajaran. Pengadian yang telah dilaksanakan di MAN 2 Padang tersebut diikuti oleh semua guru ekonomi MGMP se-Kota Padang. Hal ini dapat dilihat pada gambar berikut ini :

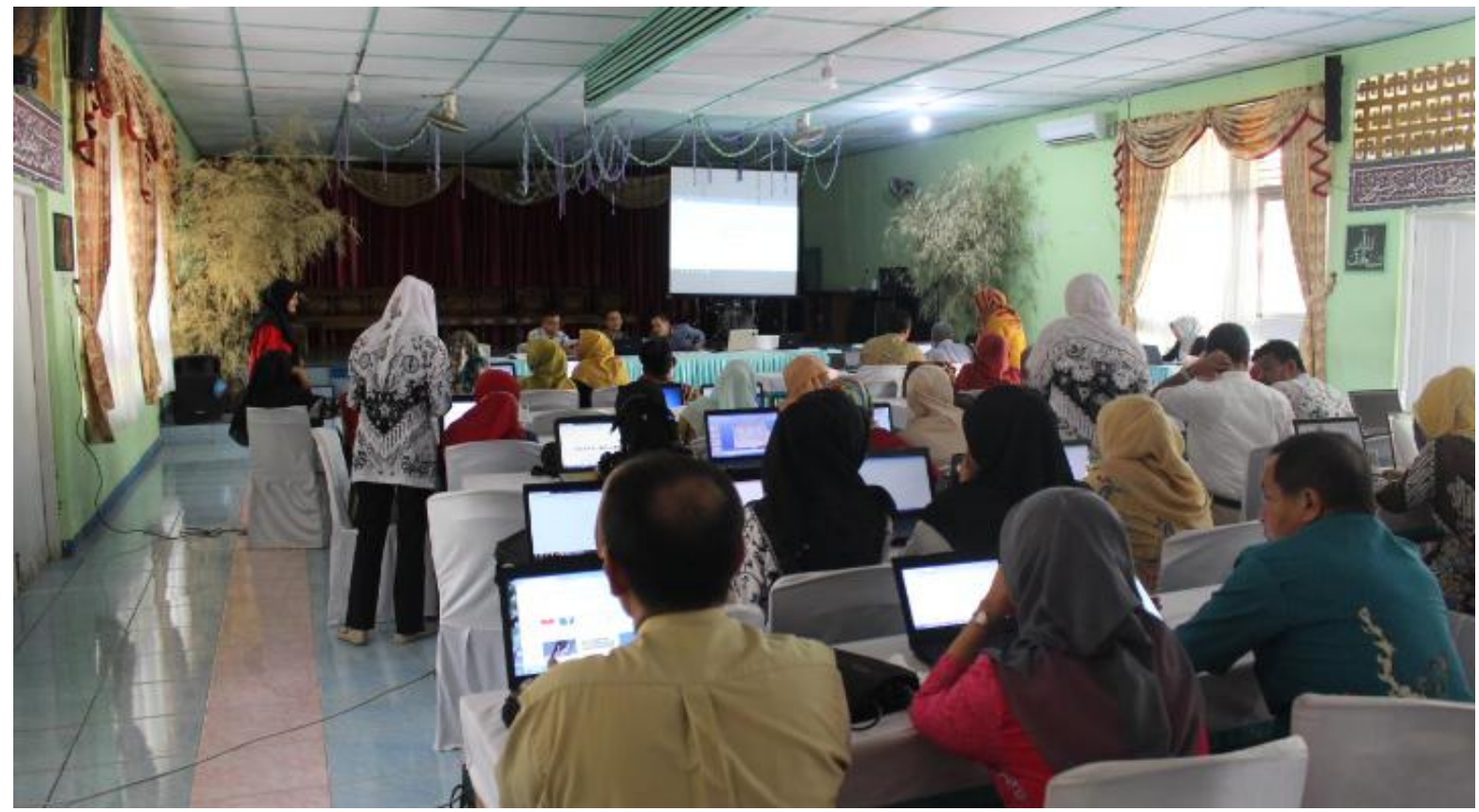

Gambar 1. Suasana pengabdian di MAN 2 Padang

Hasil yang diharapkan bisa dicapai dengan adanya pengabdian ini adalah bisa mengembangkan keaktifan siswa dalam mengkonstrusi pengetahuannya sendiri. Kemudian dengan adanya pelaksanaan pengabdian ini akan meningkatkan kemampuan guru dalam menggunakan pendekatan konstruktivisme pada proses pembelajaran dengan media pendamping edmodo.

\section{PENUTUP}

Berdasarkan kegiatan yang telah dilakukan, maka dapat disimpulkan beberapa hal sebagai berikut: kegiatan pengabdian kepada masyarakat yang dilaksanakan di MAN 2 Padang bulan Januari 2019 diikuti oleh semua guru MGMP Ekonomi se-Kota Padang berjumlah 50 orang, kegiatan ini bermanfaat bagi sekolah mitra untuk meningkatkan kompetensi guru-guru serta keterampilan guru dalam proses pembelajaran guna meningkatkan proses belajar siswa. Kegiatan pengabdian pada masyarakat ini sukses dilaksanakan di sekolah mitra dan berjalan dengan baik tanpa ada hambatan sedikit pun.

\section{Ucapan Terima Kasih}

Terima kasih kami ucapkan kepada ketua MGMP ekonomi se-Kota Padang yang telah bekerjasama dengan prodi pendidikan ekonomi, sehingga bisa terselenggaranya pengabdian ini.

\section{DAFTAR PUSTAKA}


Rangkiang: Lurnal Pengabdian Pada Masyarakat

UPSM STKIP PGRI Sumatera Barat

Vol. 1 (Juni 2019): $36-40$

Alit, Mahisa. 2004. Pembelajaran Konstruktivisme, Apa dan Badaimana Penerapannya di Dalam Kelas. Cirebon: SD Negeri 2 Bungko Lor UPT Pendidikan Kecamatan Kapetakan.

Aqib, Zainal. (2013). Model-model media dan strategi pembelajaran kontekstual (inovatif): Bandung :Yrama wijaya

Depdiknas. 2003. Kurikulum 2004, Standar Kompetensi Mata Pelajaran Sejarah untuk Sekolah Menengah Atas dan Madrasah Aliyah. Jakarta : Depdiknas.

http://help.edmodo.com/wp-content/uploads/2011/09/UserGuide_Sep11.pdf 